Research Article

\title{
Estimation of small intestinal bacterial overgrowth in children patients with different gastrointestinal symptoms
}

\author{
Dong Xi, Roger Kim, Yatian Zhang, Fernanda Kupferman, Radha Nathan*
}

Department of Pediatrics, Brookdale University Hospital and Medical Center, One Brookdale Plaza, Brooklyn, NY 11212, USA

Received: 21 December 2015

Accepted: 03 February 2016

\section{*Correspondence:}

Dr. Radha Nathan,

E-mail: rnathan@bhmcny.org

Copyright: ( ) the author(s), publisher and licensee Medip Academy. This is an open-access article distributed under the terms of the Creative Commons Attribution Non-Commercial License, which permits unrestricted non-commercial use, distribution, and reproduction in any medium, provided the original work is properly cited.

\begin{abstract}
Background: Small intestinal bacterial overgrowth (SIBO) is a condition presenting with increased bacterial colonization. Lactulose breath test (LBT) is widely used for the diagnosis of SIBO. However the clinical symptom most likely to have positive LBT is still unknown. The objective of the study was to analyze the correlation between different gastrointestinal (GI) symptoms and positive LBT, and identify the symptom with highest positive LBT rate.

Methods: Retrospective study was performed in pediatric patients who underwent LBT from 2011 to 2014. Patients presented with one or multiple GI symptoms. LBT was performed and considered to be positive if hydrogen level was increased by $20 \mathrm{ppm}$. The percentage of positive LBT in all the patients and patients with individual GI symptom was calculated. The symptom with highest positive LBT rate was identified.

Results: Totally 48 patients were tested. 34 patients (71\%) were found to have positive LBT and 14 patients (29\%) were negative. LBT was found to be positive in $85 \%$ of patients with failure to thrive, higher than other GI symptoms. Failure to thrive was identified to have highest positive LBT rate and less likely to be associated with multiple manifestations in patient with SIBO.

Conclusions: Our study showed strong correlation between positive LBT and failure to thrive, and less association of failure to thrive with multiple symptoms in SIBO. LBT should be considered in patients with failure to thrive and no other etiologies.
\end{abstract}

Keywords: SIBO, LBT

\section{INTRODUCTION}

Small intestinal bacterial overgrowth (SIBO) is a condition presenting with increased non-native and native bacterial colonization, resulting in excessive fermentation, inflammation or malabsorption. ${ }^{1-3}$ The overgrowth is believed to be the results of excess numbers of gram-negative aerobes and anaerobes, migrating from the lumen of colon to the small bowel. ${ }^{1,4,5}$

Hydrogen breath testing (HBT) is one of the techniques used in the diagnosis of SIBO.$^{6-8}$ HBT is a non-invasive, indirect diagnostic method that relies on the ability of intestinal bacteria to metabolize carbohydrate moieties that release hydrogen, including lactulose. ${ }^{9-11}$ Lactulose breath test (LBT) is based on the principle that metabolism of lactulose by contaminating bacterial flora leads to the production of an analyte, including hydrogen and methane.,12 This test is easy to be performed and with relatively high sensitivity and specificity. ${ }^{9}$

However, the majority of patients with SIBO have nonspecific clinical symptoms or can be asymptomatic. $8,11,13,14$ The clinical indication for LBT is still unclear and this brings difficulty in determining when to perform this test and in diagnosing SIBO undeferredly in children patients. Our present study was designed to address the indication of LBT by exploring 
the relationship between different gastrointestinal symptoms and positive LBT.

\section{METHODS}

Retrospective study was performed on children patients aging from 1 year to 23 years, who underwent lactulose breath test (LBT) at Brookdale University Hospital and Medical Center from 2011 to 2014. The study and protocol was approved by institution research board (IRB). 48 patients who matched the criteria were enrolled in the study.

All of children patients presented with one or multiple of the following gastrointestinal symptoms: nausea, vomiting, weight loss/slow weight gain/failure to thrive, excessive weight gain/obesity, diarrhoea, constipation, bloating and abdominal pain. During LBT, all subjects took 7.5-10g lactulose bases on the age and the levels of hydrogen and methane were monitored at $30 \mathrm{~min}, 60$ min, $90 \mathrm{~min}$, $120 \mathrm{~min}$ after ingestion of lactulose. ${ }^{9}$ LBT was considered to be positive if the level of hydrogen was increased by $20 \mathrm{ppm}$ in less than 1 hour after intake of lactulose. The percentage of positive LBT in all patients was calculated. The ratio between positive and negative test in patients with individual gastrointestinal symptom was calculated and compared. The gastrointestinal symptom with highest percentage of positive LBT was identified, which was considered to have highest associated with SIBO. Whether the above symptom is associated with other manifestations in patients with SIBO or not was described and analysed.
Data was presented as either percentage or Mean \pm SE. Results were further analysed by t-test or Two-way ANOVA followed by Bonferroni post-test. $\mathrm{P}<0.05$ was interpreted as significant difference.

\section{RESULTS}

Table 1: General information of the subjects in LBT positive and negative groups, including age and weight (Ave. means average).

\begin{tabular}{|llll|}
\hline Patient & LBT negative & LBT positive & P \\
\hline $\begin{array}{l}\text { Age } \\
\text { (year) }\end{array}$ & $\begin{array}{l}\text { Range (9mo- } \\
\text { 23yrs); Ave. }\end{array}$ & $\begin{array}{l}\text { Range (1yo2mo- } \\
\text { 20yrs); Ave. }\end{array}$ & $>0.05$ \\
& 6yo 7 mo & 7yo1mo & \\
$\begin{array}{l}\text { Weight } \\
\text { (Lb) }\end{array}$ & $\begin{array}{l}\text { Range (20- } 255 \\
\text { Lb) Ave. }\end{array}$ & $\begin{array}{l}\text { Range (25-155 } \\
\text { Lb); Ave. 62.7 }\end{array}$ & $>0.05$ \\
\hline Number & $14(29.4 \%)$ & Lb & \\
\hline
\end{tabular}

Among total 48 eligible children patient, 34 subjects (71.8\%) were found to be positive on LBT and 14 patients $(29.2 \%)$ were negative. General information of the patients in different groups was described in table 1 , including the range, average of age and weight. No significant difference was found between the baseline level of breath hydrogen in patients with negative LBT (19.0ppm \pm 5.3$)$ and with positive LBT (13.7 ppm \pm 2.5$)$ $(\mathrm{p}=0.31)$. At $60 \mathrm{~min}$ after intake of lactulose, no increase of breath hydrogen level was observed in patient with negative LBT, while patient with positive LBT showed a dramatic increase (32.4 ppm \pm 6.3$)(\mathrm{p}<0.05)$ (Figure 1B).

Table 2: Positive LBT rate in different gastrointestinal symptoms (**indicates highest rate, $p<0.05$ compared to others).

\begin{tabular}{|lllllllll|}
\hline Symptom & $\begin{array}{l}\text { Failure to } \\
\text { thrive }\end{array}$ & nausea & vomiting & $\begin{array}{l}\text { Weight } \\
\text { gain }\end{array}$ & diarrhea & constipation & bloating & $\begin{array}{l}\text { Abdominal } \\
\text { pain }\end{array}$ \\
\hline $\begin{array}{l}\text { Positive } \\
\text { LBT rate }\end{array}$ & $85 \% * *$ & $50 \%$ & $62.5 \%$ & $50 \%$ & $45.5 \%$ & $66.7 \%$ & $60.9 \%$ & $62.5 \%$ \\
\hline
\end{tabular}

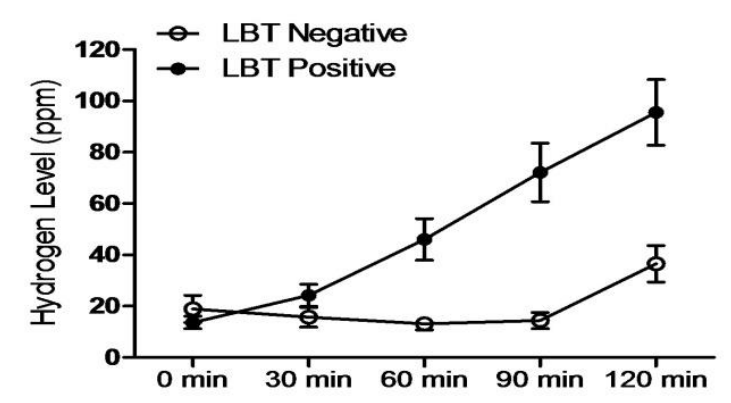

Figure 1: The curve of hydrogen levels after ingestion of lactulose in LBT negative and positive groups.

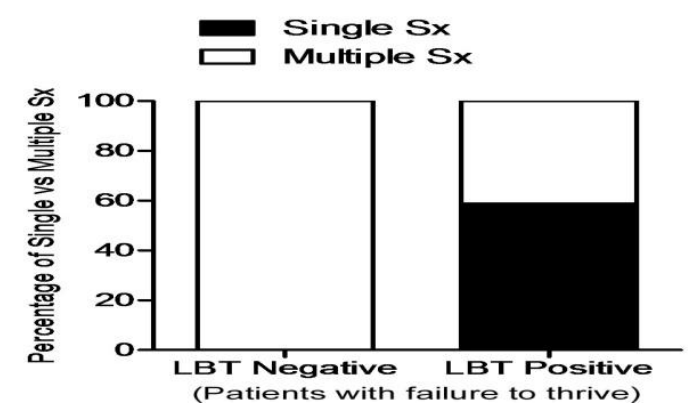

Figure 2: The percentage of single and multiple GI symptoms in LBT negative and positive patients with failure to thrive (Sx means symptom). 
Among patients with individual gastrointestinal symptom, LBT was found to be positive in $85 \%$ of patients with failure to thrive, which was significantly higher than other symptoms $(\mathrm{p}<0.05), 50 \%$ of patients with nausea, $62.5 \%$ of patients with vomiting, $50 \%$ of patients with excessive weight gain, $45.5 \%$ of patients with diarrhoea, $66.7 \%$ of patients with constipation, $60.9 \%$ of patients with bloating, and $62.5 \%$ of patients with abdominal pain. Compared to other GI manifestations, failure to thrive/weight loss/slow weight gain was identified as the symptom with highest positive LBT rate and highest relationship or association with SIBO (Table 2).

Among the patients with failure to thrive/weight loss/slow weight gain, association with other gastrointestinal symptoms was found in $100 \%$ of patients with negative LBT presented with, while only $41.2 \%$ of patients with positive LBT $(\mathrm{p}<0.05)$ (Figure 2). Additionally, $58.8 \%$ of the patients with both failure to thrive and SIBO present with single symptom of failure to thrive only, while not with multiple symptoms.

\section{DISCUSSION}

In our study, this specific symptom, failure to thrive was found to have the most significant association with SIBO. Previous reviews reported that the clinical manifestations of SIBO are quite variable. Clinical symptoms are expressed more or less according to the severity of involvement and they are modified by primary underlying diseases. ${ }^{2}$ SIBO may be clinically asymptomatic or can have non-specific symptoms. Our study, for the first time, demonstrated that failure to thrive has higher relationship with SIBO than other GI symptoms.

Previous literatures categorized the symptoms of SIBO based the severity of disease. ${ }^{8}$ Mild cases can present bloating, flatulence, abdominal discomfort, diarrhoea and abdominal pain. In severe cases, there are signs of malabsorption, presenting with weight loss, steatorrhoea and malnutrition, together with liver lesion, skin manifestation, arthralgia and deficiency syndromes like anaemia. Our study showed failure to thrive, being similar to weight loss as one of the severe symptoms, was more likely associated with SIBO. This might indicate that the patients with mild GI symptoms are less likely suffered from SIBO, while SIBO would be an important differential diagnosis in the patient with severe GI symptoms.

SIBO is an acquired disorder, well known for causing nutrient and vitamin malabsorption in patients with chronic small bowel motility failure. ${ }^{7}$ SIBO results from failure of the gastric acid barrier, failure of small intestinal motility, anatomic alterations, or impairment of systemic and local immunity. ${ }^{15,16}$ The patients with SIBO could theoretically show the symptoms due to the above pathophysiology. Nonspecific symptoms in SIBO, which were reported by previous literatures, resulted in the under-diagnosis of this disease, as no "warning symptoms" were generated for clinical practitioner.

Other comprehensive reviews reported that there was surprising little literature on the symptomatology of SIBO, and only diarrhoea, abdominal pain, bloating had been linked with any degree of consistency. ${ }^{14}$ Risk factors were also studies by other literatures, including the diseases and surgical procedures that resulted in damage to or loss of the ileocecal junction. However, the "warning symptoms" is still unclear for clinical indication of ruling out SIBO.

Our study revealed that failure to thrive may be the appropriate "warning symptom", and furthermore, failure to thrive in patients with SIBO was less likely to be associated with other multiple manifestations, including nausea, vomiting, diarrhoea, constipation, bloating and abdominal pain. This result indicated that for the patient with failure to thrive and no other symptoms, SIBO should be considered as an important differential diagnosis after other aetiologies were ruled out, including celiac disease, cystic fibrosis, etc.

In summary, out study report failure to thrive has the highest association with SIBO, and is less likely associated with other manifestations in patients with this disease. We recommend that LBT should be performed in patient with failure to thrive and no other aetiologies.

Funding: No funding sources

Conflict of interest: None declared

Ethical approval: The study was approved by the Institutional Ethics Committee

\section{REFERENCE}

1. DuPont AW, DuPont HL. The intestinal microbiota and chronic disorders of the gut. Nat Rev Gastroenterol Hepatol. 2011;8:523-31.

2. Quigley EM. Small intestinal bacterial overgrowth: what it is and what it is not. Curr Opin Gastroenterol. 2014;30:141-6.

3. Schiller LR. Evaluation of small bowel bacterial overgrowth. Curr Gastroenterol Rep. 2007;9:373-7.

4. Malik BA, Xie YY, Wine E. Diagnosis and pharmacological management of small intestinal bacterial overgrowth in children with intestinal failure. Can J Gastroenterol. 2011;25:41-5.

5. Gutierrez IM, Kang KH, Calvert CE. Risk factors for small bowel bacterial overgrowth and diagnostic yield of duodenal aspirates in children with intestinal failure: a retrospective review. J Pediatr Surg. 2012;47:1150-4.

6. Abu-Shanab A, Quigley EM. Diagnosis of small intestinal bacterial overgrowth: the challenges persist! Expert Rev Gastroenterol Hepatol. 2009;3:77-87. 
7. Bohm M, Siwiec RM, Wo JM. Diagnosis and management of small intestinal bacterial overgrowth. Nutr Clin Pract. 2013;28:289-99.

8. Bures J, Cyrany J, Kohoutova D. Small intestinal bacterial overgrowth syndrome. World J Gastroenterol. 2010;16:2978-90.

9. Khoshini R, Dai SC, Lezcano S. A systematic review of diagnostic tests for small intestinal bacterial overgrowth. Dig Dis Sci. 2008;53:1443-54.

10. Leiby A, Mehta D, Gopalareddy V. Bacterial overgrowth and methane production in children with encopresis. J Pediatr. 2010;156:766-70, 770 e1.

11. Sieczkowska A, Landowski P, Kaminska B. Small Bowel Bacterial Overgrowth in Children: A Comprehensive Review. J Pediatr Gastroenterol Nutr. 2015.

12. Korterink JJ, Benninga MA, van Wering HM. Glucose hydrogen breath test for small intestinal bacterial overgrowth in children with abdominal pain-related functional gastrointestinal disorders. J Pediatr Gastroenterol Nutr. 2015;60:498-502.
13. Sieczkowska A, Landowski P, Zagozdzon P. Small Bowel Bacterial Overgrowth Associated with Persistence of Abdominal Symptoms in Children Treated with a Proton Pump Inhibitor. J Pediatr. 2015;166:1310-2.e1.

14. Quigley EM, Abu-Shanab A. Small intestinal bacterial overgrowth. Infect Dis Clin North Am 2010;24:943-59.viii-ix.

15. Collins BS, Lin HC. Double-blind, placebocontrolled antibiotic treatment study of small intestinal bacterial overgrowth in children with chronic abdominal pain. J Pediatr Gastroenterol Nutr 2011;52:382-6.

16. Tahan S, Melli LC, Mello CS. Effectiveness of trimethoprim-sulfamethoxazole and metronidazole in the treatment of small intestinal bacterial overgrowth in children living in a slum. J Pediatr Gastroenterol Nutr. 2013;57:316-8.

Cite this article as: Xi D, Kim R, Zhang Y, Kupferman F, Nathan R. Estimation of small intestinal bacterial overgrowth in children patients with different gastrointestinal symptoms. Int J Contemp Pediatr 2016;3:385-8. 